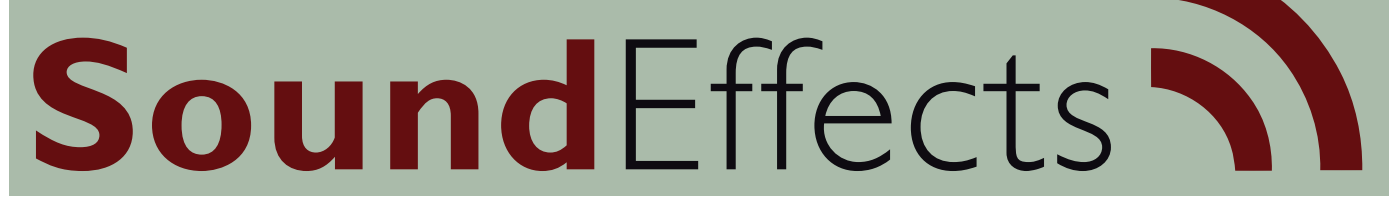

An Interdisciplinary Journal of Sound and Sound Experience

\title{
Penelope Gouk
}

\section{Music and the emergence of experimental science in early modern Europe}

\author{
Dr Penelope Gouk \\ Honorary Research Fellow \\ School of Arts, Histories and Cultures \\ University of Manchester \\ UK \\ gouk@manchester.ac.uk
}




\begin{abstract}
The seventeenth century witnessed major advances in physics and experimental science. This paper argues that while the role of new visual technologies (e.g. the microscope) has been well studied, less attention has been paid to acoustic technologies in early modern natural philosophy. In particular, I attend to the relationship between making music, a specific form of organised sound mediated through instruments, and the production of new scientific knowledge. On the one hand, this relationship developed in the context of acoustics, a new discipline first mapped out by Francis Bacon. On the other hand, music's relationship to natural philosophy was also more fundamental, since harmony was understood as an organising principle of the universe, the laws of musical strings providing a model for other forms of vibrative motion. I also show the importance of musical training for Galileo's experiments and the significance of harmony for Isaac Newton and Robert Hooke.
\end{abstract}

\title{
Sound and science
}

The seventeenth century was a remarkable period in the history of science, notable for major advances in mathematical physics and the experimental study of nature (Henry, 1997; Dear, 2001). There were several characteristic features of this new experimental practice, the most striking being the use of instruments to generate reliable scientific data. Nature was now being manipulated, via the use of technology, to give up her secrets. Another characteristic was the successful application of mathematics to the physical world, notably in the fields of astronomy, mechanics and optics. Both space and time were subjected to more and more precise measurement, as newly-invented instruments, such as the telescope (1609) and spring balance watch (1660), were developed. It was Galileo Galilei who in his book Il Saggiatore (The Assayer) of 1623 insisted that the universe operated according to mathematical principles, while it was Isaac Newton's revolutionary book Principia Mathematica or The Mathematical Principles of Natural Philosophy of 1687 that contained the three laws of motion, which dominated the scientific view of the universe for the next three hundred years and beyond.

There has been considerable discussion about the broader cultural context of this new experimental trend in early modern Europe. In particular, debate has focused on the growing importance of observation to Westerners (Alpers, 1983; Wilson, 1995), at the same time that literacy and the ability to assimilate visual data increased due to the impact of the printing press (Eisenstein, 1979; Johns, 2000). One long-standing argument has been that early modern Western culture developed a distinctively visualist bias at the expense of the other senses (McLuhan, 1962; Ong, 1970; Smith 2007). Ong's thesis in particular was that premodern and nonliterate societies are 
predominantly aural-oral in character and consequently have a magical conception of the world. He claimed that literate, scientific societies, on the other hand, chiefly rely on sight, where the rational observer is effectively detached from the world that he surveys. Ong argued that an epistemic shift from hearing to vision took place in the sixteenth and seventeenth centuries, as Europeans became increasingly literate and, therefore, more modern and scientific in outlook. Scholars such as Michel Foucault (1970), Svetlana Alpers (1983) and David Harvey (1990) continued this visualist argument to the point that it is now taken for granted that new visual technologies since the Renaissance (e.g. the telescope and microscope) dramatically altered how Westerners came to imagine and even to dominate the world.

Academic focus on the eye may itself reflect a bias in Western perception, but it does mean that there is a huge gap in early modern sensory history that is only slowly being filled by sensory studies in general (Smith, 2007) and sound studies in particular (Burnett et al., 1991; Johnson, 1995; Smith, 2004; Cockayne, 2007; Gouk 2007). Musicologists have shown that some striking changes took place in musical practices in the sixteenth and seventeenth centuries, a process involving new instruments and modes of performance as well as new ways of listening to and responding to music (Butt \& Carter, 2005). Given the active nature of early modern Western visuality, should we not also consider how new aural technologies and sound organisation may have affected Western hearing and thinking at the same time as they transformed the European soundscape?

Although mostly framed around a different question, namely music's relationship to the broader scientific movement that was taking place in this period, a significant body of research by those interested in the impact of musical sound on early modern Western thought deserves our attention (Cohen, 1984; Coehlo, 1992; Kassler, 1995; Gouk, 1999; Gozza, 2000; Wardhaugh, 2008). Cohen was the first to identify three different 'scientific' approaches towards understanding musical consonance, which were mathematical, mechanical and experimental in nature, respectively. He focused on several notable seventeenth-century figures who tackled the problem, including Johannes Kepler, Galileo Galilei, Marin Mersenne and Christiaan Huygens. Gozza located these examples within a broader temporal framework and argued for an overall shift from 'number' being regarded as the essential basis for harmony - a position which dated from Antiquity - towards 'sound', where the physical motion of vibrating bodies was regarded as more fundamental to music's nature. However, in his more recent study of musical science in late seventeenth-century England, Wardhaugh concluded that both approaches were still alive around 1700 and that the rise of mathematical acoustics did not immediately bring about the demise of musical ratio theory.

A somewhat different perspective on music's relationship to philosophical thought is offered by Kassler's research which, like Wardhaugh's and also my own, has concentrated on English sources. One important theme that Kassler first iden- 
tified is the role that musical models played in developing understandings of the mind-body relationship and of an inner sense of self, most notably the models of Thomas Hobbes, Robert Hooke and Francis North. My own research has shown how these models of inner space, the microcosm, were inextricably linked to musical models of the macrocosm, which emphasised harmony, both as a dynamic property and as an organising principle of nature. However, what I chiefly want to draw attention to in this paper is the surprisingly intimate connection between making music and the emergence of experimental science, mediated through the use of instruments (Gouk, 2005). At the heart of my work is the claim that developments in musical practice had a perceivable impact on how philosophers thought about nature, the realm of scientific knowledge. (The reverse is also true, namely that the performance of music was sometimes influenced by natural philosophy, particularly in attempts to promote specific tuning systems; see for example Salmon, 1705.) As I have already indicated, the related concepts of harmony and sympathy proved to be powerful models for those who would grasp the dynamic structure of the cosmos. Although these topics have been explored by others, my distinctive contribution to the debate is that instead of a simple relationship between music and the new science, music was also strongly implicated in the natural magic of the period, a practice which involved secret powers in nature to bring about extraordinary effects (Gouk, 1999). In this regard, my work complements that of Gary Tomlinson (1993), who highlighted the role that music played in the magical theory of the Renaissance, with particular emphasis on Italian sources from the late fifteenth century to around 1600 (see also Walker, 1958). Indeed, as Leigh Schmidt has shown (2000), there was still a strong association between marvellous acoustic effects and magic in eighteenth-century America, although by this time its practice had considerably less status than around 1600.

To understand what magic had to do with both music and science, it is important to recognise that knowledge was classified somewhat differently from today in the early modern period. Thus, for example, the term science (scientia) simply meant theory or systematic knowledge of a discipline, while art (ars) denoted its practical application. As Vincenzo Galilei, the father of Galileo, observed in his Dialogo della musica antica et moderna (1581):

[T] he sciences have a different way of proceeding and a different aim for their activity than the arts. The sciences search for the truth of all the characteristics and properties of their subject, together with their causes, having as goal knowledge of the truth and nothing more. The arts instead have as their goal an operation, something different from understanding. (p. 105)

The idea of practising science was therefore a contradiction in terms. Rather than science I prefer the contemporary term 'natural philosophy', which means wisdom 
about nature, while the ability to bring about effects mostly fell in the category of 'natural magic', a practice which attracted considerable attention in the decades around 1600. In brief, magic in general was an art which either used supernatural agency to bring about marvellous effects (this was demonic magic) or else relied on secret (occult) forces in nature to bring about the same extraordinary results; this was known as natural or spiritual magic. Within this conceptual framework, music might be regarded 'as [...] a magicall charme', because of its power over the imagination, bringing about changes in mood or behaviour by hidden means (Bright, 1586, p. 241).

\section{Music's place in the system of knowledge}

We will return later to natural magic, but first I want to draw attention to music's place in the system of knowledge and how this has changed over the passage of time. Nowadays music is classified as a performing art, yet until the middle of the eighteenth century it was generally counted among the mathematical disciplines, specifically the branch of mathematics known as harmonics (Gouk, 2002; Christensen 1993). In its narrowest sense, harmonics was the study of the mathematical relations underlying the structure of audible music. But there was also a broader conception of harmonics, which went back to Ptolemy and even Plato, a tradition which assumes that the structures of music have their analogues in the soul and in the heavens, and, therefore, astronomy and music are intimately related. Four major treatises on universal harmony were published in the early seventeenth century: Robert Fludd's Utriusque cosmi historia (History of the macrocosm and microcosm, 1617), Johannes Kepler's Harmonia mundi (Harmony of the world, 1619), Marin Mersenne's Harmonie universelle (Universal harmony, 1636) and Athanasius Kircher's Musurgia universalis (Universal music-making, 1650). All of these authors believed, like Galileo, that the universe was constructed mathematically and that the ratios of musical intervals were an important component of that structure.

At the same time, this essentially Platonic view of music as sounding mathematics was complemented by its place among the liberal arts. Thanks to Aristotle and his followers, music was understood to be linked to poetry and oratory, a means of enhancing the power of words through song and, therefore, having a direct influence on morals and behaviour. During the Renaissance it became fashionable among the nobility to practice art music themselves, which accordingly gained high social and intellectual status (Castiglione, 1528). At the same time, the revival of ancient texts unknown to the Middle Ages provided a rich vein of resources, which alluded to music's quasi-miraculous powers in Antiquity, effects which some philosophers thought might be reproduced in modern times if the right kind of instruments and performance techniques could be discovered (Walker, 1958). 
One of the most important musical figures in the ancient world was Pythagoras, who was believed to be Plato's teacher. On the theoretical side, legend taught that Pythagoras was the first to discover the numerical relationships governing musical consonance (the octave being in the ratio of 1:2, the fifth 2:3 and the fourth 3:4) and to show that the same ratios governed the distances between planets, starting from Earth at the centre of the universe to Saturn. He was also credited with the invention of the monochord, an instrument which demonstrated these relationships experimentally through string length ratios. On the practical side, Pythagoras was reputed to cure diseases and modify passions through the power of his singing and playing on the lyre, instrumental skills he possessed because of his unparalleled knowledge of harmony in nature. In other words, Pythagoras was understood to have practised a form of natural magic. As I will demonstrate, these stories exercised an important influence on early modern philosophical thought, in both a positive and negative sense.

\section{Francis Bacon}

An ambiguity towards ancient philosophy is particularly noticeable, for example, in the work of Francis Bacon, who unlike his contemporary Robert Fludd had little time for Pythagoras. Bacon is important here because of his ambition to develop an experimental method for generating new and improved kinds of knowledge, including a new physics. How this method was supposed to work can be demonstrated through a study of the discipline he first identified in Latin as acoustica in 1623 and discussed in more detail in his Sylva sylvarum which was published posthumously in 1626 (Gouk, 1999, ch. 5). It is important to note that Bacon referred to this work as a 'higher kind of natural magic', which explains why it presents a range of unusual phenomena and exhorts the reader to investigate their hidden causes. In fact, Bacon actually rejected most forms of magic as illegitimate, but thought he could create a new, useful kind that would avoid the pitfalls of normal magical practice.

The Sylva was divided into a thousand 'Experiments' (one hundred in each of the ten chapters) that were to provide an empirical basis for discovering the fundamental causes of various phenomena. Within this experimental framework, sound, including music and the voice, was treated as a significant source of power that could be controlled to bring about effects on things and people. One aim was the perfection of instruments to communicate secretly or over long distances or to improve hearing range; in other words, the speaking trumpet and hearing trumpet. Most significantly, however, Bacon sought to investigate the nature of music, on the grounds that most music theory was full of 'mystical subtleties' and little truth (Experiment 101). Nevertheless, the deep concern with which Bacon mapped out his acoustical programme in the Sylva hints at the link with Renaissance natural magic, in which practical music occupied an honoured, eminent position. 
In particular, Bacon emphasised the importance of studying harmony, 'the sweetest and best harmony [being], when every part, or instrument, is not heard by itselfe, but a conflation of them all' (Experiment 225). One source of inspiration for Bacon's observations seems to have been the music he heard at the English court, which under the early Stuarts had the largest musical household in Europe. For example, he evidently paid attention to experiments by the king's private players, who were using different configurations of instruments in their consort music, since he notes that:

All concords and discords of music are, (no doubt) sympathies, and antipathies of sounds. And so (likewise) in that Music, which we call broken music or consort music; some consorts of instruments are sweeter than others (a thing not sufficiently yet observed) [...] but for the melioration of music, there is yet much left to try and enquire. (Experiment 278)

Bacon also referred to an extensive range of musical instruments from brass to strings and proposed a series of experiments to see how the materials used in their construction, as well as the length and thickness of strings or pipes, determined qualities such as pitch or what we would call timbre.

Apart from the investigation of 'harmony', Bacon was certain that his experimental method could also uncover the cause of 'sympathy', a topic fundamental to occult philosophy as one of the organising principles of the universe. A more localised source of interest for Bacon was that court musicians and instrument makers were exploring different ways of using sympathetic resonance to enrich their music making. For example, there was the polyphant invented by Daniel Farrant, which was strung with a course of sympathetic strings running beside the strings actually being played. The phenomenon could also be demonstrated simply by showing that a musical tone produced by a string on one lute can cause a string on another instrument, tuned at the unison or octave, to vibrate. In natural magic this kind of action at a distance, where the cause of the sympathetic relationship between two vibrating strings was hidden, served as a model for other mysterious forces in nature (Porta, 1589). Yet despite this suggestive link between music and the cosmos, Bacon rejected the idea of a musically-configured universe and the reliance on harmony as an omnibus explanation for phenomena. In his experimental philosophy music was to be studied as part of physics, in the context of the new discipline of acoustics. Within this scheme, musical instruments effectively became philosophical or scientific instruments which would lead to the understanding of the 'great secret of numbers, and proportions' governing musical consonance (Experiment 186).

Bacon's ideas came to exercise a growing influence, especially on his English followers. A number of his 'experiments' and similar investigations were actually carried out during the course of the seventeenth century, as the field of acoustics developed. 
However, I should point out that Bacon himself was more of a philosopher than an experimentalist, because he does not seem to have undertaken any research himself into musical phenomena (nor indeed into any other field of enquiry that he mapped out so carefully). Also, we should be wary of accepting Bacon's suggestion that prevailing music theory was mostly useless or that no one before him had engaged in musical experiments. Although he would have been unaware of the fact, it turns out that one person in particular had already been active in investigating the nature of musical consonance, inspired it seems by no less a figure than Pythagoras. Not coincidentally for my argument, this individual was none other than the Florentine musician Vincenzo Galilei, father of the more illustrious Galileo. The fact that father and son were both skilled in music was a crucial element in their respective experimental work.

\section{The Galilei experiments}

Vincenzo Galileo's musical experiments took place some time in the 1580s within the context of a group of Florentine poets and musicians, who were dedicated to recovering the glory of ancient Greek dramatic music. This lost sonic art had apparently powerfully moved the emotions. The group's approach was to interrogate ancient sources coupled with experiments in setting verse to instrumental accompaniment to see if this emotional effect could be recreated in modern times. From the perspective of music history the most interesting outcomes of this activity were the invention of monody, an affective vocal solo line with chordal harmony, and the development of opera. From the perspective of the history of science, however, one significant but unintended outcome was the first documented attempt to test the results of a series of experiments apparently performed some two thousand years earlier (Palisca, 1992).

As I have already explained, it was Pythagoras who was credited with a discovery known since Antiquity: that the musical consonances of the octave, fifth and fourth could be expressed in terms of simple arithmetical ratios that corresponded to string lengths; the understanding being that the faster a string moved the higher the pitch. However, it is important to know that until the seventeenth century there was no understanding or proof that pitch is proportional to frequency or that frequency is also dependent on other variables, such as the tension and thickness of a string or the length and width of a pipe etc., nor was it known that the oscillations of a vibrating string are isochronous (that is, independent of amplitude) and that this property is similar to that of pendulums, which also vibrate isochronously (within limits). Instead, music theorists followed the sixth-century philosopher Boethius in stating that the cause of consonance lay in the numbers that represented the musical consonances. The Boethian tradition taught that Pythagoras discovered 
the correspondence between simple numerical ratios and the musical consonances, when he went past a forge and heard the blacksmiths' hammers give off harmonious sounds in relation to each other.

Pythagoras supposedly weighed the different hammers, each of which made a particular musical sound. Reportedly, he discovered an arithmetical relationship between the weights of the hammers and their respective pitches, which can be expressed as 12:9:8:6, and then he went on to invent the monochord, which exhibits the same arithmetical relationships between the string lengths that produce the octave, fifth and fourth, in other words, the ratios 1:2, 2:3 and 3:4. It was also thought that the same simple integers corresponding to pitches are found in the weights stretching equal strings, in the lengths of musical pipes and other sounding bodies. Although it might seem remarkable, no one seems to have checked and verified Pythagoras's findings for nearly two thousand years.

Vincenzo Galilei seems to have put Pythagoras to experimental trial in the late 1580 s while Galileo was living with him in Florence. Through repeated trials Vincenzo discovered that a variety of ratios other than those using 1 to 4 and their multiples could cause consonance in glasses, pipes and strings. In particular, he discovered that weights suspended from strings in the ratio 2:1 did not produce the octave. Instead, Vincenzo found that to make strings of equal length sound an octave apart, weights have to be in the squared proportion 4:1, not 2:1. He also demonstrated on his lute that pitch in strings can be varied not just by length or tension, but also by changing their thickness or the material of which they are made. Although Vincenzo did not establish any laws, he nevertheless undermined the fundamental principles that had previously governed consonance. The story of Pythagoras was shown to be untrue. Also, significantly, he had made a real musical instrument the subject of theoretical analysis, making it in effect a piece of laboratory equipment.

With his father's example in mind it should perhaps be no surprise that Galileo's musical training, specifically as a lutenist, equipped him with cognitive skills that were to serve him well in his attempt to find an accurate way to measure the motion of falling bodies (Drake, 1970). His musical proficiency involved a sharp ear, an ability to tune the lute and other instruments accurately, and a well-developed sense of musical time, in particular the ability to measure small, equal divisions of time for a sustained period. It turns out that these technical skills were highly relevant to Galileo's new experimental method which he began developing in the early decades of the seventeenth century.

One major problem was that none of the timekeepers that were available to him were precise enough to measure speed accurately. Galileo researched the characteristics of pendulums in his early career and subsequently tried to use them as time measurement devices in his later experiments. In 1638 Galileo published his Discorsi or Discourses concerning two new sciences in which he presents his first law of the 
pendulum together with the laws of falling bodies and inclined planes, all of which had been discovered partly through a process of experimenting with specially constructed instruments. The law is that the frequency of a pendulum is inversely proportional to the square root of its length. (In other words, if a pendulum of one unit of length vibrates once a second, a pendulum of four units [2 squared] vibrates every two seconds.) The context in which Galileo describes the isochronous motion of pendulums is essentially musical, and indeed it is possible to concur with Drake that he could not have created his motion experiments without the musical training that he had received from his father.

One of Galileo's motion experiments in particular shows how important his musical training was for developing new techniques of measurement. This experiment involved rolling a ball repeatedly down an inclined plane, around which a series of frets were tied. These frets were gradually adjusted, so that the bumping sounds that occurred when the ball went over them finally came at half second intervals: precise units of time which Galileo was able to calculate with a high degree of accuracy. The idea of using adjustable frets was most likely to occur only to a lutenist or viol player, who would be accustomed to using this technique for fretting instruments. More significantly, however, Galileo's experiment relied crucially on the musician's internalised 'clock' as a means of marking small, equal units of time over a sustained period. Drake argued that from this experiment later came Galileo's idea for a timing device which used the weight of the water flowing during the swing of a pendulum to establish the rule I have already described; that is, quadrupling the length of the pendulum doubles the duration of its swing, leading to his discovering the law of the acceleration of falling bodies.

\section{Marin Mersenne}

Another important figure in the quest for more accurate measurement was the French Minim friar Marin Mersenne, the author of Harmonie universelle (1636). This book was meant to be a compendium of everything a musician should know, a body of knowledge which included the physical and mathematical properties of musical sound, which he dealt with in the first volume before moving on to discuss performance and musical instruments (Cohen, 1984). Mersenne believed that the universe is constructed harmonically, and that these cosmic proportions govern the principles of musical practice. Mersenne's contribution to seventeenth-century acoustics and musical science can hardly be overestimated. During the 1620s and 1630s he engaged in a comprehensive investigation into the nature of sound. Musical instruments provided him with experimental apparatus for investigating many different properties of sound, not just pitch. Also drawing on the empirical knowledge of instrument makers and performers, Mersenne's publications were unparalleled in 
their breadth of coverage and depth of detail about the structure, properties and tunings of specific instruments, thus providing a vital source of information on seventeenth-century performance practice.

From a scientific perspective, Mersenne's most significant contribution was his discovery of the rules governing the vibration of musical strings and pendulums. In modern terms, he established: first, that frequency is inversely proportional to string length (i.e. the shorter the string the higher the note, so that if a string two units in length has a frequency of $220 \mathrm{Hertz}$, a string one unit long has a frequency of $440 \mathrm{Hertz}$ ). Second, he established that frequency is proportional to the square root of string tension (i.e. the higher the tension, the higher the frequency, so that if 1 kilo gives $220 \mathrm{Hertz}$, then 4 kilos give $440 \mathrm{Hertz}$ ). Thirdly, Mersenne established that frequency is inversely proportional to the square root of the string's thickness (i.e. the thinner the string, the higher the frequency, so that if a string 4 millimetres thick gives $220 \mathrm{Hertz}$, a string 1 millimetre thick gives $440 \mathrm{Hertz}$ ). He also discovered, independently of Galileo, that the frequency of a pendulum is inversely proportional to the square root of its length (i.e. if a pendulum 4 units long vibrates once every two seconds, a pendulum 1 unit long vibrates every second). 'Mersenne's laws', as they are known today, provided a powerful model for other natural philosophers searching for quantitative laws in the physical world. Through a regular correspondence about his experiments and their mathematics, he certainly got the young Christiaan Huygens (whose father was also a noted lutenist and song-writer) interested in the science of music and its relationship to the motion of pendulums. This proved to be vital for the latter's invention of the pendulum clock, which Huygens patented in 1657.

Mersenne also recognised that his laws might have practical applications. For example, he suggested that the pendulum might prove useful to musicians for maintaining standards of pitch and time. In fact, evidence of musicians keeping time with the help of pendulums dates from the 1660s, shortly after Huygens developed the pendulum clock. Mersenne had also thought that the pendulum might prove useful to physicians measuring the human pulse. In fact, the first pulse watches appeared in the 1690s, based on the technology of the spring balance that had first been applied to clocks and watches by Huygens and the English natural philosopher Robert Hooke some time around 1660.

\section{Universal harmony and the new science}

This mention of Hooke brings us to his activities in the newly-founded Royal Society, the first public scientific institution which was established in 1660. Hooke was appointed as the Society's first Curator of Experiments and was therefore responsible for its weekly experimental agenda. As a result, musical topics played some part 
in these early meetings, not least because Hooke himself was interested in music. In particular, he was interested in the physics of musical instruments, including sympathetic resonance, and the musical laws of Mersenne, which were among the earliest quantitative laws to be established. It is notable, for example, that when music became a subject of discussion at a Society meeting in February 1662 it was explicitly linked to theories of vibration and time measurement (Gouk, 1999).

The year 1664 was particularly fruitful for musical topics. In July and August Hooke performed a series of experiments which demonstrated the validity of Mersenne's laws, which we will see formed the basis of his theory of matter. In October of the same year a curious instrument called the archiviol was presented to members. This was a kind of barrel organ in the shape of a keyboard instrument in which the strings are set in motion by a parchment bow turned by a handle. However, few musical activities seem to have taken place in the Society during the rest of the century, even though Hooke himself was evidently still interested in musical topics, most notably between 1672 and 1676 (Gouk, 1999; Wardhaugh, 2008).

Although Hooke never published systematically on his cosmological theories, he left sufficient evidence to show that his conception of the universe (the macrocosm) and of human nature (the microcosm) was fundamentally musical. In an unpublished manuscript written some time in the 1670s he observed that nature acts regularly and geometrically and that 'God by nature has framed our bodies also according to geometrical rules'. He went on to say that:

Men have a body harmoniously constructed and an harmonious soule to be affected thereby/ twas Pythagoras and divers others of the ancient philosophers that by search and enquiry found out the true reason of it, which I suppose might be one of the reasons why he and Plato asserted the soul to be made of numbers. (In Kassler \& oldroyd, 1983)

For Hooke one of the key demonstrations of this principle is the process of music perception, where a clear correspondence can be made between the vibrations of a musical string and the perception of a musical tone, the ear functioning like a resonating instrument. In this regard, he followed Mersenne in the assumption that the more frequently musical vibrations strike the ear, the higher the pitch perceived. From this principle came the explanation for the perception of consonance, namely that the more frequently the vibrations of two musical tones coincide with each other, the more pleasing their sound (Cohen, 1984; Kassler, 1995).

Underpinning Hooke's experimental work was a theory of matter which visualised the universe as being made up of tiny particles that act like vibrating strings, their motions following Mersenne's laws. This analogy agreed with his discovery of what is now known as Hooke's Law of elasticity, which states that the extension of a spring is in direct proportion with the load added to it. (For example, if a 
spring extends by 2 centimetres for a mass of 1 kilo, then it extends by 4 centimetres for a mass of 2 kilos.) Hooke also suggested that a vibrating spring is dynamically equivalent to a pendulum. For Hooke, the fact that vibrating bodies such as strings followed demonstrable musical laws was sufficient to argue that the same laws were followed by much smaller, invisible bodies which constituted the basic building blocks of nature. The differences in their frequency provided Hooke with a basis for explaining variety in fluids and solids, and phenomena such as gravitational attraction. Just as the three factors determining pitch are length, tension and 'bigness' (cross-sectional area), so the analogous properties of matter or substance, figure or shape, and body or bulk are those which determine frequency in particles of matter. He explained his argument in the following passage of his Micrographia of 1665 , a pioneering work based on his discoveries of hitherto invisible realms through use of the compound microscope:

\footnotetext{
[P]articles that are all similar, will, like so many musical strings equally stretch't, vibrate together in a kind of harmony or unison; whereas others that are dissimilar [...] [will] make quite differing kinds of vibrations and repercussions, so that [both types of particle] may be [...] mov'd, yet are their vibrations so different [...] that they [...] cannot agree together, but fly back from each other to their similar particles. (Micrographia, p. 15)
}

This analogy goes some way towards explaining why Hooke's musical experiments made for the Royal Society were not just a case of proving Mersenne correct. It was on the basis of simple and verifiable experiments using strings and other vibrating bodies that Hooke could claim analogous principles were operating beyond the range of ordinary sense perception. The justification by experiments that could be reliably witnessed and reproduced was one of the basic principles of the early Royal Society's new scientific method, and, for Hooke at least, musical experiments proved to be among the most significant of these demonstrations.

\section{Isaac Newton}

For my last example of music's place in the emergence of the new science I will turn to Isaac Newton, who in 1687 laid down the fundamental laws governing planetary motion. There are two aspects of his Principia Mathematica that relate to earlier parts of this paper. The first of these concerns Newton's success in analysing sound waves and deriving the speed of sound from the first principles of dynamics (Dostrovsky, 1974-1975). What interests me most is the model which enabled him to describe sound propagation mathematically. In brief, he made an analogy between the motion of a pendulum and particles of air oscillating backwards and forwards like tiny pendulums, each one obeying the laws of simple harmonic motion. In 
effect, he translated Hooke's intuitive, qualitative model of matter in motion into one expressed in precise mathematical terms. Up to this point the vibrating string and the physical pendulum had embodied earlier understandings of what we now call harmonic motion. Now these were replaced, not by another physical model, but a mathematical relation. After Newton this process of abstraction became accepted as a standard mathematical tool independent from the physical realm, and musical models were no longer needed.

The second feature of the Principia I want to comment on is the broader intellectual context within which Newton placed his own achievements. It may seem strange to us today, but Newton did not see himself as a pioneer of universal gravitation. Instead, in a draft addition to the Principia written around 1694, he looked back to Pythagoras as a mathematician and philosopher who, like himself, had discovered the fundamental laws of motion (McGuire \& Rattansi, 1966). Newton seems to have genuinely believed that the law of gravity was understood in ancient times, but that this knowledge was hidden from all but a few rare individuals who transmitted it secretly. In Newton's interpretation of the legend of Pythagoras visiting the blacksmiths, Pythagoras first discovered by experiment the inverse square relationship in the weights of hammers. From this discovery, he went on to apply the same principle to the heavens:

[A]nd consequently by comparing those weights with the weights of the planets, and the lengths of the strings with the distances of the planets, he understood by means of the harmony of the heavens that the weights of the planets towards the Sun were reciprocally as the squares of the distances from the Sun [in other words the inverse square law]. (In McGuire \& Rattansi, pp. 116-117)

In his draft notes Newton explains that Pythagoras concealed this knowledge from ordinary men, while at the same time revealing it to initiates, such as himself, by means of allegory and symbolism. This explains why Newton took the story of Pythagoras discovering the simple ratios which governed consonance in the weights of the hammers seriously, whereas, as we have already seen, a century earlier Vincenzo Galileo dismissed that part of the legend, because it was incorrect. For Newton, however, this error was no accident; indeed, it was made deliberately to hide the truth about planetary motion. He believed that Pythagoras assumed any true philosopher would check the story of the hammers by experiment. On finding that the weight ratios were squared reciprocals, he would realise that the myth contained a hidden truth about the harmony of the cosmos, namely that Pythagoras was explaining the inverse square law theory of gravity, rather than simply the characteristics of musical ratios. However, Newton never published this material, and it never became part of mainstream scientific thought. Instead, Newton himself was recognised as discovering the law of gravity, while, at the same time, the 
idea that the universe was constructed according to musical principles gradually lost its force.

\section{Conclusion}

In this paper I have shown various ways that music was integral to the transformation of scientific thought in the seventeenth-century Scientific Revolution, the point at which physics became a properly mathematical discipline. Galileo and his father, for example, were skilled lutenists whose intimate knowledge of the technology of their instruments not only led them to investigate the properties of vibrating strings, but also taught them how to measure musical time at a period when there were no mechanical timekeepers accurate enough to perform this task. Having proposed his new science of acoustics, Bacon urged natural philosophers to investigate the properties of musical instruments to discover the cause of harmony. Mersenne, on the other hand, actually carried out such investigations, leading him to discover the laws governing musical strings and the frequency of pendulums. These were among the earliest quantitative laws of the seventeenth century, the validity of which could be demonstrated to the eye and verified by the ear through experiment.

A generation later, Hooke and Huygens were actively constructing devices for objective measurement, using the principles of controlled vibration that Mersenne had established: namely the pendulum clock and the spring balance watch. Hooke also used Mersenne's laws as a basis for his fundamental theory of the universe. And finally Newton, who transcended all these musical analogies and relationships with his advanced use of mathematical concepts, which underpinned many forms of natural phenomena from gravity to music. Thus, we see that it was partly the use of musical instruments, not just what we would call scientific or mathematical instruments, which provided a subject sufficiently complex and sufficiently simple to be analysed experimentally and mathematically. The cognitive skills required for making music at a high level, particularly the ability to distinguish small units of time and pitch space, proved to be essential in the development of a universal measure. In other words, musical instruments and their sounds provided an important context in which seventeenth-century natural philosophers began to develop experimental and mathematical science as we now understand it. 


\section{References}

Alpers, S. (1983). The art of describing: Dutch art in the seventeenth century. Chicago and London.

Bright, T. (1586). A Treatise of Melancholy. London: John Windet.

Burnett, C., Fend, M., \& Gouk, P. (Eds.). (1991). The second sense: studies in hearing and musical judgement from antiquity to the seventeenth century. London: The Warburg Institute.

Butt, J., \& Carter, T. (Eds.). (2005). The Cambridge history of seventeenth-century music. Cambridge: Cambridge University Press.

Castiglione, B. (1528; Eng. trans. T. Hoby 1561). The Book of the Courtier. London: Wyllyam Seres.

Cockayne, E.J. (2007). Hubbub. New Haven and London: Yale University Press.

Cohen, H.F. (1984). Quantifying music: the science of music at the first stage of the scientific revolution, 15801650. Dordrecht: D. Reidel.

Christensen, T. (1993). Rameau and musical thought in the Enlightenment. Cambridge: Cambridge University Press.

Dear, P. (2001). Revolutionizing the sciences: European knowledge and its ambitions 1500-1700. Princeton: Princeton University Press.

Dostrovsky, S. (1974-1975). Early vibration theory: physics and music in the seventeenth century. Archive for the History of Exact Sciences, 14, 169-218.

Drake, S. (1970). Renaissance music and experimental science. Journal of the History of Ideas, 31, 483500.

Eisenstein, E.L. (1979). The printing press as an agent of change: communications and cultural transformations in early-modern Europe. Cambridge: Cambridge University Press.

Foucault, M. (1970). The order of things: an archeology of the human sciences. London: Tavistock Publications Ltd.

Gouk, P. (1999). Music, science and natural magic in seventeenth-century England. New Haven and London: Yale University Press.

Gouk, P. (2002). The role of harmonics in the Scientific Revolution. In: Christensen, T. (Ed.), The Cambridge history of Western music theory (pp. 223-245). Cambridge: Cambridge University Press.

Gouk, P. (2005). Music and the sciences. In: Butt, J., \& Carter, T. (Eds.), The Cambridge history of seventeenth-century music (pp. 132-157). Cambridge: Cambridge University Press.

Gouk, P. (2007). In search of sound: authenticity, healing and redemption in the early modern state. Senses and Society, 2, 303-328.

Gozza, P. (Ed.). (2000). Number to Sound: the Musical Way to the Scientific Revolution. Dordrecht: Kluwer.

Harvey, D. (1990). The condition of postmodernity: an enquiry into the origins of cultural change. Cambridge, MA and Oxford: Basil Blackwell Ltd.

Henry, J. (2002). The Scientific Revolution and the origins of modern science (2nd ed.). Houndsmills and London: Palgrave.

Johns, A. (2000). The nature of the book: print and knowledge in the making. Chicago: Chicago University Press.

Johnson, J.H. (1995). Listening in Paris: a cultural history. Berkeley: University of California Press.

Kassler, J.C., \& Oldroyd, D. (1983). Robert Hooke's Trinity College 'Musick Scripts', his music theory and the role of music in his cosmology. Annals of Science, 40, 559-595.

Kassler, J.C. (1995). Inner music: Hobbes, Hooke and North on internal character. London: Athlone Press.

McGuire, J.E., \& Rattansi, P.M. (1966). Newton and the "Pipes of Pan". Notes and Records of the Royal Society of London, 21, 108-143.

McLuhan, M. (1962). The Gutenberg galaxy: the making of typographic man. Toronto.

Ong, W.J. (1970). The presence of the word. New York.

Palisca, C.V. (1992). Was Galileo's father an experimental scientist? In: Coelho, V. (Ed.), Music and science in the age of Galileo (pp. 143-151). Dordrecht: Kluwer Academic Publishers.

Porta, Giambattista della (1589). Magiae naturalis libri XX. Naples: H. Salvianum. 
Salmon, T. (1705). The Theory of Musick reduced to Arithmetical and Geometrical Proportions, by the Rev. Mr Thomas Salmon. Philosophical Transactions, 24, 2072-2077.

Schmidt, L.E. (2000). Hearing things: religion, illusion, and the American Enlightenment. Cambridge, MA and London: Harvard University Press.

Smith, M.M. (Ed.). (2004). Hearing history: a reader. Athens, GA: University of Georgia Press.

Smith, M.M. (2007). Sensory history. Oxford: Berg.

Tomlinson, G. (1993). Music in Renaissance magic: toward a historiography of others. Chicago and London: Chicago University Press.

Walker, D.P. (1958). Spiritual and demonic magic from Ficino to Campanella. London: Warburg Institute.

Wardhaugh, B. (2008). Music, experiment and mathematics in England 1653-1705. Farnham, UK and Burlington, US: Ashgate.

Wilson, C. (1995). The invisible world: early modern philosophy and the invention of the microscope. Princeton: Princeton University Press. 